\title{
Effect of digester F/M ratio on gas production and sludge minimization of ultrasonically treated sludge
}

\author{
Gözde T. Köksoy and F. Dilek Sanin
}

\begin{abstract}
Sludge pretreatment by mechanical, chemical or thermal methods before anaerobic digestion has been applied to increase the digestability of excess sludge. Pretreatment processes rely on their ability to disrupt cell membranes and to release organic materials from the cells into the aqueous phase. Pretreatment by mechanical disintegration has grown rapidly in recent years in parallel with the advances in technology. Ultrasonic sludge disintegration -one of the most commonly used mechanical pretreatment methods- enables the occurrence of cavitation bubbles for the break-up of microorganism cells to extract intracellular materials. The purpose of this study was to conduct disintegration experiments to optimize sonication parameters and to operate subsequent batch anaerobic digesters to examine the effect of food to microorganism ratio (F/M) in sonicated and unsonicated samples. Results showed that high sonication powers and longer treatment times were effective in sludge disintegration in terms of soluble chemical oxygen demand release. Sonicated sludge digested in batch reactors with higher initial F/M ratio caused higher methane generations, higher sludge reductions and had better dewatering characteristics. Key words | activated sludge, anaerobic digestion, biogas, disintegration, F/M ratio, ultrasonication
\end{abstract}

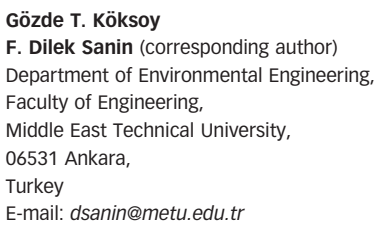

\section{INTRODUCTION}

Anaerobic digestion is the most commonly applied sewage sludge stabilization technique resulting in the reduction of sludge volatile solids and the production of biogas. However, anaerobic stabilization is a slow process; because the first step in digestion, biological hydrolysis, has been identified as a slow and rate-limiting step. Therefore, long residence times in the fermenters and large fermenter volumes are required for digestion (Eastman \& Ferguson I98I; Shimizu et al. I993; Show et al. 2006; Appels et al. 2008).

In order to improve the hydrolysis rate, various types of sludge pretreatment methods have been studied. These methods lead to disintegration of floc structure and rupture of the cell membrane of microorganisms in waste activated sludge, resulting in the release of organic substances outside the cell (Wang et al. I999). Pretreatment doi: $10.2166 /$ wst.2010.447 may be performed biologically, chemically, thermally, mechanically or by a combination of these methods (Bougrier et al. 2005).

Ultrasonication is one of the most effective mechanical methods that is used commonly for pretreatment. Its mechanism depends on the formation of cavitation bubbles by sound waves. There are several parameters that affect the efficiency of sonication as a pretreatment method on waste activated sludge. Typically, before the full scale installation of ultrasound unit, lab scale and pilot scale experiments are carried out to analyze these parameters. Sonication power and time are among the most important parameters of sonication systems (Khanal et al. 2007).

Food to microorganism (F/M) ratio is calculated by the ratio of the amount of substrate (waste activated sludgeWAS) to the inoculum (anaerobic digested sludge-ADS) 
added to anaerobic digesters. It is an important parameter for digesters operated in batch mode indicating volatile solids loading into the system. A high $\mathrm{F} / \mathrm{M}$ ratio indicates higher organic loading (per unit amount of anaerobic microorganisms) to the digester whereas low $\mathrm{F} / \mathrm{M}$ ratio shows that the loading is small. As the $\mathrm{F} / \mathrm{M}$ ratio gets too high it may be inhibitory or toxic and as it gets too low it may prevent induction of enzymes necessary for biodegradation. (Grady 1985; Prashanth et al. 2006). Prashanth et al. (2006) studied the F/M values ranged from 0.18 to 2.0 and found the best value to be between $0.57-0.68$ for anaerobic digestion of synthetic wastewater. This issue has also been studied for different types of substrates such as straw (Hashimoto 1989), maize (Raposo et al. 2006) and food waste (Forster-Carneiro et al. 2008). In addition, Braguglia et al. (2006) studied the effect of feed to inoculum (F/I) ratio on anaerobic digestion of sonicated sludge. The focus of the study was on the kinetics of digestion and gas production during a 12 day digestion process. They observed that sonication improved the first order hydrolysis constant, however, the rate constant first decreased with increasing $\mathrm{F} / \mathrm{I}$ ratio from 0.1 to 1 , then increased back with the increase in F/I ratio from 1 to 2 . Our focus in this study is to operate reactors over a wider $\mathrm{F} / \mathrm{M}$ ratio range, with the aim of addressing the changes in biogas production and the concerns of sludge reduction following digestion.

The objective of this study is therefore to evaluate the effect of sonication applied under different conditions on WAS to determine the best operating conditions and to observe the effect of $\mathrm{F} / \mathrm{M}$ ratio on batch anaerobic digestion process operated with sonicated and unsonicated WAS.

\section{METHODS}

\section{Sludge and ultrasound disintegration}

Waste activated sludge (WAS) and anaerobically digested sludge (ADS) were obtained from Ankara Central Wastewater Treatment Plant. The plant operates a conventional biological treatment system that includes screening, primary clarification, secondary treatment by activated sludge system and sludge treatment by gravity thickener, anaerobic digestion and belt filter dewatering. WAS was taken from the recycle stream of activated sludge tank. ADS was sampled from the full scale digester of the plant fed with primary and secondary sludge.

The disintegration by ultrasound was performed with an ultrasonic homogenizer Labsonic P (Sartorius AG, Germany) operating at maximum power of $400 \mathrm{~W}$ and a frequency of $24 \mathrm{kHz}$. The power has amplitude of $20-100 \%$. The probe used in the experiments has a diameter of $22 \mathrm{~mm}$ and is suitable for sample volumes $100-2,000 \mathrm{ml}$. This probe provided a power of $255 \mathrm{~W}$ and a sonication density of $0.73 \mathrm{~W} / \mathrm{ml}$ for a $350 \mathrm{ml}$ of WAS sample sonicated during the experiments.

By controlling the amplitude of homogenizer (20 to $100 \%$ ) different ultrasonic powers were applied to the samples. The time was also controlled to determine the effect of different sonication times. At various magnitudes of power and time combination studied, the energy provided to sludge varied between 2.2 and $54.6 \mathrm{~kJ} / \mathrm{gTS}$. Disintegration studies were performed in an ice bath in order to control temperature between $25-30^{\circ} \mathrm{C}$.

\section{Anaerobic digestion tests}

In the experiments, $250 \mathrm{ml}$ serum bottles were used as batch anaerobic reactors. For each set triplicate reactors were constructed. The reactors were fed with WAS (either untreated or sonicated) and ADS at required $\mathrm{F} / \mathrm{M}$ ratios calculated as given by Equation (1).

$\frac{\mathrm{F}}{\mathrm{M}}=\frac{\mathrm{MLVSS}_{\mathrm{WAS}} \times V_{\mathrm{WAS}}}{\mathrm{MLVSS}_{\mathrm{ADS}} \times V_{\mathrm{ADS}}}$

where MLVSS is the mixed liquor volatile suspended solids of WAS or ADS added as mg/L and $V$ is the volume of WAS or ADS added in $\mathrm{ml}$. F/M ratios studied were $0.5,2,5$, and 10 .

The working volume of serum bottle reactors was $120 \mathrm{ml}$. Of this total volume, $100 \mathrm{ml}$ was WAS and ADS (their individual amounts depended on $\mathrm{F} / \mathrm{M}$ ratio) and $20 \mathrm{ml}$ was basal medium. The aim of using basal medium was to supply nutrients to the system and help to adjust the $\mathrm{pH}$. Basal medium components are given in Table 1. The remaining volume of the reactor was left empty for gas collection. 
Table 1 | Basal medium components

\begin{tabular}{|c|c|}
\hline $2.58 \mathrm{~g} / \mathrm{L} \mathrm{KH}_{2} \mathrm{PO}_{4}$ & $0.3 \mathrm{mg} / \mathrm{L} \mathrm{MnCl}_{2} \cdot 4 \mathrm{H}_{2} \mathrm{O}$ \\
\hline $4.788 \mathrm{~g} / \mathrm{L} \mathrm{Na}{ }_{2} \mathrm{HPO}_{4} \cdot 7 \mathrm{H}_{2} \mathrm{O}$ & $2,847.31 \mathrm{mg} / \mathrm{L} \mathrm{NaEDTA} \cdot 2 \mathrm{H}_{2} \mathrm{O}$ \\
\hline $0.6 \mathrm{~g} / \mathrm{L} \mathrm{NaHCO} 3$ & $1.8 \mathrm{~g} / \mathrm{L} \mathrm{NH}_{4} \mathrm{Cl}$ \\
\hline $0.3 \mathrm{~g} / \mathrm{L} \mathrm{ZnCl}{ }_{2}$ & $0.48 \mathrm{~g} / \mathrm{L} \mathrm{Na}_{2}(\mathrm{Mo}) \mathrm{O}_{4} \cdot 2 \mathrm{H}_{2} \mathrm{O}$ \\
\hline $0.78 \mathrm{~g} / \mathrm{L} \mathrm{MgCl}_{2} \cdot 6 \mathrm{H}_{2} \mathrm{O}$ & $299.93 \mathrm{mg} / \mathrm{L} \mathrm{CoCl} 2 \cdot 6 \mathrm{H}_{2} \mathrm{O}$ \\
\hline $0.72 \mathrm{~g} / \mathrm{L} \mathrm{CaCl} 2 \cdot 2 \mathrm{H}_{2} \mathrm{O}$ & $549.6 \mathrm{mg} / \mathrm{L} \mathrm{NiCl} 2 \cdot 6 \mathrm{H}_{2} \mathrm{O}$ \\
\hline $16.8 \mathrm{~g} / \mathrm{L} \mathrm{FeSO} \cdot 7 \mathrm{H}_{2} \mathrm{O}$ & $6 \mathrm{ml} / \mathrm{L}$ (concentrated) $\mathrm{HCl}$ \\
\hline $0.3 \mathrm{mg} / \mathrm{L} \mathrm{H}_{3} \mathrm{BO}_{3}$ & $556.8 \mathrm{mg} / \mathrm{L} \mathrm{CuSO}{ }_{4} \cdot 5 \mathrm{H}_{2} \mathrm{O}$ \\
\hline $718.62 \mathrm{mg} / \mathrm{L} \mathrm{Al}_{2}\left(\mathrm{SO}_{4}\right)_{3} \cdot 18 \mathrm{H}_{2} \mathrm{O}$ & \\
\hline
\end{tabular}

Once filled, all reactors were purged with $\mathrm{N}_{2}$ for 10 minutes to prevent oxidation of readily oxidizable organics and remove oxygen from the system. The tops of the bottles were closed with rubber stoppers, and shaken well. Finally, reactors were incubated at $37^{\circ} \mathrm{C}$ by shaking them manually once a day.

\section{Analytical procedures}

Mixed liquor suspended solids (MLSS) and mixed liquor volatile suspended solids (MLVSS) were analyzed in preliminary studies to measure sludge solids content before and after anaerobic digestion tests, to adjust the $\mathrm{F} / \mathrm{M}$ ratio and to analyze the solids destruction. The samples were analyzed using Standard Method 2540D and 2540E (APHA AWWA WEF 2005) for MLSS and MLVSS measurements, respectively.

To analyze the organic content in the soluble phase, before and after sonication, samples were settled for $2 \mathrm{~h}$, the supernatants were centrifuged for $10 \mathrm{~min}$ at 3,500 rpm and then centrates were filtered through $0.45 \mu \mathrm{m}$ pore size membrane filters. Soluble COD of supernatants were measured in duplicates, by USEPA approved colorimetric method (Jirka \& Carter 1975) using Hach kits and Hach DR2000 spectrophotometer. In order to analyze the organic content in sludge, total COD was measured in duplicates by the same method.

Turbidity is caused by suspended matter, organic and inorganic matter, soluble colored organic compounds and microorganisms. In order to measure turbidity, the supernatant of the sludge was put into turbidity measurement cell after 2 hour settlement and analyzed using Hach Turbidimeter $2100 \mathrm{~N}$ in three replicate samples.

The dewatering property was measured with capillary suction time (CST) applying Standard Method 2710G (APHA AWWA WEF 2005). For each sample, CST was measured in triplicates with Type $304 \mathrm{M}$ Triton Electronics Capillary Suction Timer.

During batch digestion period, total gas production and gas composition were analyzed at predetermined time intervals. Total gas volume produced in the reactors was measured by an open-tube manometer. The gas composition in the reactors was analyzed by a GC equipped with TCD (Agilent Technologies 6890N). The carrier gas in the system was helium at an average velocity of $29 \mathrm{~cm} / \mathrm{sec}$. Gas composition analysis was made with $30.0 \mathrm{~m} \times 530 \mu \mathrm{m} \times 40.0 \mu \mathrm{m}$ HP-Plot Q capillary column. Oven temperature program was as follows: temperature was kept at $45^{\circ} \mathrm{C}$ for $1 \mathrm{~min}$, and then increased to $65^{\circ} \mathrm{C}$ by $10^{\circ} \mathrm{C}$ at a minute.

\section{RESULT AND DISCUSSION}

\section{Sludge disintegration tests}

In disintegrated sludge, because of the floc break-up with the sonication process, extracellular and intracellular materials pass into the liquid phase and increase the soluble COD values. Results of the disintegration study (Figure 1) show that, when sonication energy input as power $\times$ time (W min) increase, soluble COD values increase as well. Figure 1 indicates when the sonication energy applied is increased to $2,550 \mathrm{~W}$ min (sonication density $0.73 \mathrm{~W} / \mathrm{ml}$ ),

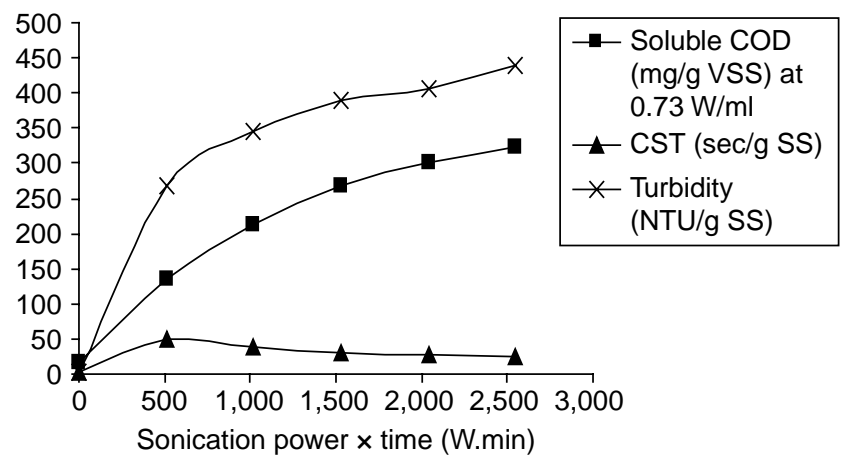

Figure 1 | Change in soluble COD, CST and turbidity with respect to sonication energy 
the soluble COD gradually increases from 17 to $322 \mathrm{mg} / \mathrm{g}$ VSS. These results show that high ultrasound power generates high mechanical shear forces during cavitation bubble implosion (Grönroos et al. 2005) and causes higher degradation of flocs and higher release of COD.

In the study of Chu et al. (200I), 20\% of the total COD turned to soluble state at $0.33 \mathrm{~W} / \mathrm{ml}$ after 120 min sonication time. Therefore, the soluble COD in the supernatant increased 40 times. Show et al. (2006) obtained an increase in the ratio of soluble COD to total COD from 3.2 to $5.4 \%$ after sonication at $92 \mathrm{~W} / \mathrm{cm}^{2}$. Furthermore, Wang et al. (2006) examined the release in soluble COD concentration at sonication times of 5, 15 and $20 \mathrm{~min}$ at TS content of $3 \%$, frequency of $20 \mathrm{kHz}$ and ultrasonic density of $0.768 \mathrm{~W} / \mathrm{ml}$. Increase in the soluble COD from 2,581 to $7,509 \mathrm{mg} / \mathrm{L}$ was obtained when the sonication time was increased from 5 to $15 \mathrm{~min}$. However, after the sonication time of $20 \mathrm{~min}$, the soluble COD release slowed down significantly.

Sonication pretreatment disintegrates the sludge flocs and particle size decreases (Chu et al. 200I). With the broken floc structure, the turbidity of the soluble phase increases. The turbidity increases gradually with the increase in sonication energy all the way to $2,550 \mathrm{~W}$ min as shown in Figure 1.

The filterability was measured using CST to estimate the ability of sludge to dewater. With the disintegration of sludge and the increase in particle number, the bound water linked to the particle surfaces increases. This, as well as the decrease in particle size due to floc break-up makes deterioration in filterability. According to literature, the CST value of the sludge disintegrated at lower powers increase (Hall 198I). Similar to findings in the study of Chu et al. (200I), in Figure 1 it is obvious that when sonication energy increases, CST values increase significantly as an indication of disintegration. Thereby, the dewaterability of sludge deteriorates. Moreover, at high sonication energies, CST values decrease compared to the CST values at lower energies. The reason of this decrease in CST values could be the effect of reflocculation. However, similar to the results reported in literature (King \& Forster I990), it was found that even though there was a decrease in CST with higher energies, at all time CST value of sonicated sludge was higher than that of untreated sludge.
Table 2 | WAS and ADS volumes added to the control and sonicated reactors for different $\mathrm{F} / \mathrm{M}$ ratios

\begin{tabular}{lllll} 
F/M ratio & $\begin{array}{l}\text { WAS }(\mathbf{m l}) \\
\text { Control }\end{array}$ & Sonicated & $\begin{array}{l}\text { ADS }(\mathbf{m l}) \\
\text { Control }\end{array}$ & Sonicated \\
\hline 0.5 & 33 & 36 & 67 & 64 \\
2 & 67 & 70 & 33 & 30 \\
5 & 83.5 & 85 & 16.5 & 15 \\
10 & 91 & 92 & 9 & 8 \\
\hline
\end{tabular}

\section{Anaerobic digestion tests}

In order to examine the effect of different $\mathrm{F} / \mathrm{M}$ values, batch anaerobic reactors with total volume of $250 \mathrm{ml}$ were set. Using the results of sludge disintegration tests, WAS sonicated at $255 \mathrm{~W}$ and $10 \mathrm{~min}$ and ADS were added to the reactors with F/M ratios at 0.5, 2, 5 and 10. In order to satisfy these ratios, WAS and ADS were added to the reactors after determining their solids contents. Table 2 shows the amounts of WAS and ADS added to the control and sonicated reactors. Reactors were set in triplicates and the results presented here are the averages from these triplicate reactors.

Figure 2 illustrates the cumulative methane production values of reactors operated at different $\mathrm{F} / \mathrm{M}$ ratios during 48 days of anaerobic digestion. For the first few days, when the $\mathrm{F} / \mathrm{M}$ ratio increases the methane produced runs lower. This means that during the first few days of digestion, the higher F/M reactors show some lag and act disadvantaged. This is possible due to the relatively low content of seed microorganisms (ADS) as seen in Table 2. After this initial "fall-behind" period, methane produced from reactors

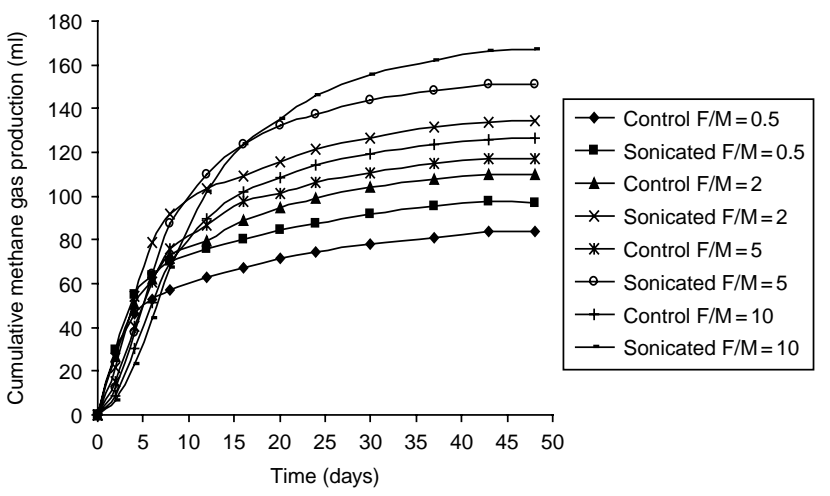

Figure 2 | The daily change in cumulative methane gas production of reactors at different $\mathrm{F} / \mathrm{M}$ ratios during anaerobic digestion. 
at high $\mathrm{F} / \mathrm{M}$ ratio catches up with and passes those of lower $\mathrm{F} / \mathrm{M}$ ratio reactors. In all cases, the sonicated reactors produce higher amounts of methane compared to their unsonicated counterparts. Besides, the three top methane producing reactors are the ones set-up with sonicated sludge samples (F/M 10, F/M 5 and F/M 2 in decreasing order). The same trend is seen for total gas production (sum of methane and carbon dioxide) from the reactors (data not shown). At the end of 48 days of digestion, results obtained from all the reactors point out that, sonicated reactors with $\mathrm{F} / \mathrm{M}$ ratio of $0.5,2,5$ and 10 produce 15.4 , 22.4, 29.3 and 32.3\% higher amounts of methane compared to their own control reactors, respectively. These small scale reactors indicate that it is possible to load the batch digesters operating to treat sonicated sludge with higher amounts of WAS to increase the gas production up to an $\mathrm{F} / \mathrm{M}$ ratio of 10 .

Since the anaerobic degradation is only possible in the presence of organic waste, specific methane production amounts are typically calculated by normalizing the methane produced with the amount of organic matter present (either VS or COD) in the system. So cumulative methane productions obtained from all the reactors at the end of digestion period are normalized with the initial total COD value present in the reactors and is presented in Figure 3. In this normalization the TCOD value of WAS was used since the ADS used in the reactors produce negligible amounts of methane. These results show that the specific

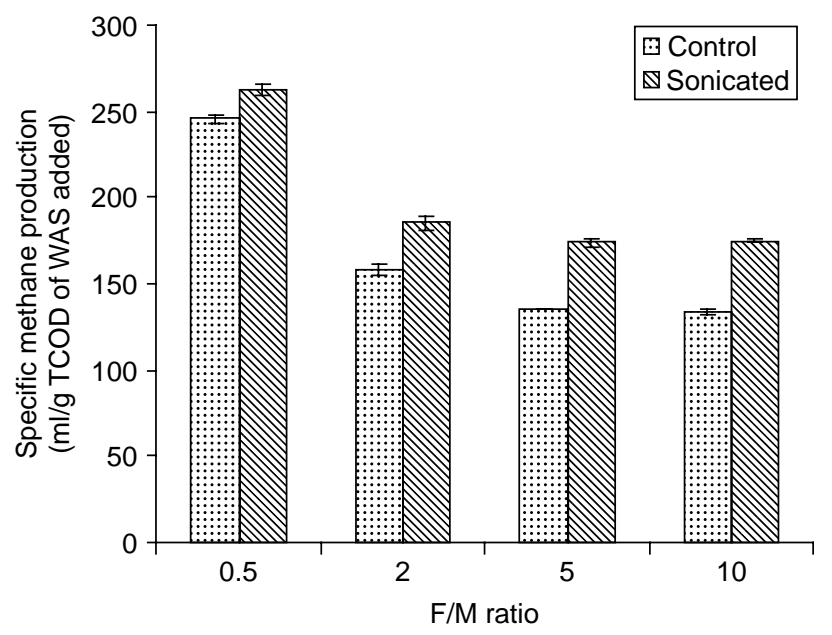

Figure 3 | Cumulative methane produced in reactors at different F/M ratios normalized with TCOD of WAS added. methane production values range between 130 and $265 \mathrm{ml} / \mathrm{g}$ TCOD. In addition it can be seen that sonicated reactors with $\mathrm{F} / \mathrm{M}$ ratio of $0.5,2,5$ and 10 caused higher specific methane productions by $6.5,16,29$ and $32 \%$, respectively compared to their own control reactors.

With these results, the lowest difference between sonicated reactor and its control in terms of total gas and methane production is found in the reactors with $\mathrm{F} / \mathrm{M}$ ratio of 0.5 . This difference is high when the $\mathrm{F} / \mathrm{M}$ ratio is 10 , obviously because more soluble organics due to disintegration by ultrasound added to reactors increase the gas amount. A decrease in specific methane production amount is observed as the F/M ratio is increased from 0.5 to 2 . From there onwards though, the specific methane production values stay more or less the same for other $\mathrm{F} / \mathrm{M}$ ratios studied. So at this point the suggestion would be to operate the batch digesters at a higher $\mathrm{F} / \mathrm{M}$ ratio if the purpose is to get solely higher methane volumes (as shown in Figure 2). However, if the purpose is to obtain higher methane productions per gram of TCOD added; lower F/M ratios look more advantaged. Due to the fact that increasing TCOD values are used in normalizing the methane produced, the higher $\mathrm{F} / \mathrm{M}$ ratios become disadvantaged due to division of methane production values by a higher number each time.

Sonication is a process used not only to increase the efficiency of anaerobic digesters, but to decrease the quantity of sludge solids to be disposed of at the end of treatment operations. To assess the potential of sludge minimization, total MLSS and MLVSS of reactors at the day of reactor set-up and at the end of anaerobic digestion period are analyzed and tabulated in Tables 3 and 4 .

Tables 3 and 4 show that the highest MLSS and MLVSS values measured in the first day (initial) are for the control reactors. Both tables show that the first day MLSS and MLVSS values of the reactors set by sonicated sludge are measured lower. That is because during pretreatment by sonication, some portion of solids was solubilized and passed into the filtrate. Considering a similar solubilization of MLSS and MLVSS would be experienced in any type of reactor (lab scale and full scale) as a natural consequence of sonication and knowing that right before sonication all sludges came from the same batch, the initial MLSS concentration for the sonicated reactors were taken as 
Table 3 | MLSS values of reactors with different $F / M$ ratios before and after anaerobic digestion

\begin{tabular}{llll} 
Reactor & $\begin{array}{l}\text { Initial MLSs } \\
(\mathbf{m g} / \mathbf{L})\end{array}$ & $\begin{array}{l}\text { Final MLSS } \\
(\mathbf{m g} / \mathbf{L})\end{array}$ & $\begin{array}{l}\text { Decrease } \\
(\%)\end{array}$ \\
\hline Control F/M $=0.5$ & 8,874 & 6,590 & 25.8 \\
Sonicated F/M = 0.5 & 8,498 & 6,495 & 26.8 \\
Control F/M = 2 & 7,746 & 4,900 & 36.7 \\
Sonicated F/M = 2 & 7,107 & 4,340 & 44.0 \\
Control F/M = 5 & 7,198 & 4,515 & 37.3 \\
Sonicated F/M = 5 & 6,494 & 4,015 & 44.2 \\
Control F/M = 10 & 6,949 & 3,985 & 42.7 \\
Sonicated F/M = 10 & 6,207 & 3,880 & 44.2 \\
\hline
\end{tabular}

the same value as their control reactor and the sludge reductions were calculated in reference to these numbers. The same application was valid for the MLVSS reduction calculations. From the results an increasing reduction in MLSS and MLVSS is obvious with the increasing $\mathrm{F} / \mathrm{M}$ ratios. In addition, the sludge solids reduction estimated by MLSS and MLVSS is higher in reactors constructed with sonicated samples compared to the ones constructed with unsonicated samples. These results point out significant sludge quantity reductions especially achievable with sonication application and subsequent reactor operation at $\mathrm{F} / \mathrm{M}$ ratios of 2 and 5 .

There is a significant increase in total COD destruction in sonicated reactors at all $\mathrm{F} / \mathrm{M}$ ratios compared to their control counterparts as shown in Table 5.

In addition with the increase of $\mathrm{F} / \mathrm{M}$ ratio, the COD reductions are enhanced. When sludge is sonicated, approximately 47, 54 and $64 \%$ of TCOD reductions are

Table 4 | MLVSS values of reactors with different F/M ratios before and after anaerobic digestion

\begin{tabular}{llll} 
Reactor & $\begin{array}{l}\text { Initial MLvss } \\
(\mathbf{m g} / \mathbf{L})\end{array}$ & $\begin{array}{l}\text { Final MLvss } \\
(\mathbf{m g} / \mathbf{L})\end{array}$ & $\begin{array}{l}\text { Decrease } \\
(\%)\end{array}$ \\
\hline Control F/M $=0.5$ & 4,436 & 2,650 & 40.3 \\
Sonicated F/M = 0.5 & 4,251 & 2,430 & 45.2 \\
Control F/M = 2 & 4,432 & 2,005 & 54.8 \\
Sonicated F/M = 2 & 4,073 & 1,745 & 60.6 \\
Control F/M = 5 & 4,430 & 1,935 & 56.3 \\
Sonicated F/M = 5 & 3,994 & 1,645 & 62.9 \\
Control F/M = 10 & 4,429 & 1,720 & 61.2 \\
Sonicated F/M = 10 & 3,957 & 1,680 & 62.1 \\
\hline
\end{tabular}

Table 5 | Total COD values of reactors with different F/M ratios before and after anaerobic digestion

\begin{tabular}{llll} 
Reactor & $\begin{array}{l}\text { Initial TCOD } \\
(\mathbf{m g} / \mathbf{L})\end{array}$ & $\begin{array}{l}\text { Final TCOD } \\
(\mathbf{m g} / \mathbf{L})\end{array}$ & $\begin{array}{l}\text { Decrease } \\
(\%)\end{array}$ \\
\hline Control F/M $=0.5$ & 6,940 & 4,972 & 28.4 \\
Sonicated F/M =0.5 & 7,080 & 4,620 & 34.8 \\
Control F/M = 2 & 6,550 & 3,931 & 40.0 \\
Sonicated F/M = 2 & 6,640 & 3,538 & 46.7 \\
Control F/M = 5 & 6,630 & 3,495 & 47.3 \\
Sonicated F/M =5 & 6,730 & 3,067 & 54.4 \\
Control F/M = 10 & 6,800 & 2,936 & 56.8 \\
Sonicated F/M = 10 & 7,020 & 2,553 & 63.6 \\
\hline
\end{tabular}

achievable with reactors operated at $\mathrm{F} / \mathrm{M}$ ratios of 2,5 and 10 , respectively.

As shown in Figure 4, dewaterability of sludge improves significantly for sonicated reactors compared to control reactors especially at low F/M ratios of 0.5 and 2 . This improvement decreases when $\mathrm{F} / \mathrm{M}$ ratio increases. In fact, CST itself decreases by the increasing $\mathrm{F} / \mathrm{M}$ ratio. These results indicate that higher $\mathrm{F} / \mathrm{M}$ ratios operated in anaerobic batch digesters help with the dewaterability of sludge and improve this property.

Turbidity of the supernatants from the sonicated reactors at different $\mathrm{F} / \mathrm{M}$ ratios decreases compared to control reactors (Figure 5). This finding indicates that the fine particulates originating particularly from sonication are rapidly removed by anaerobic digestion process.

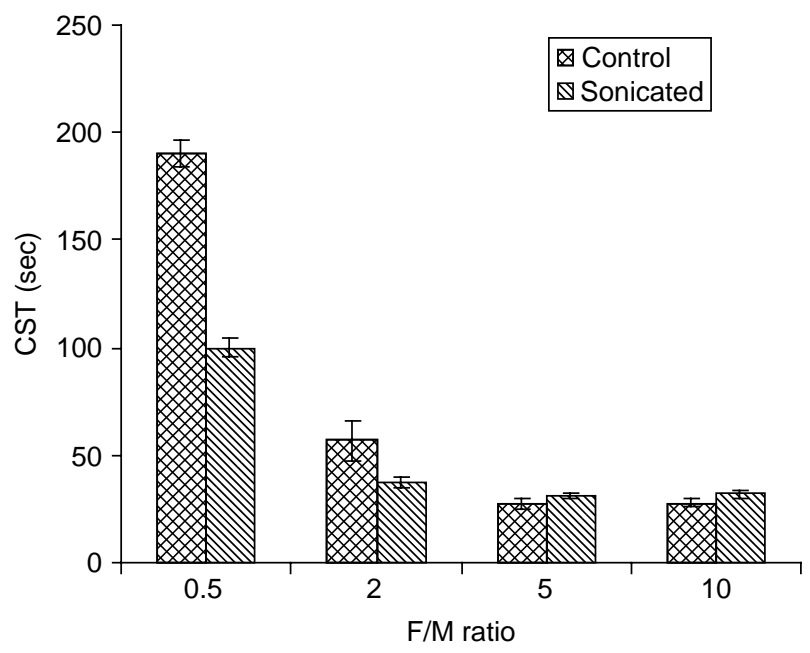

Figure 4 | CST values of reactors at different F/M ratios after digestion. 


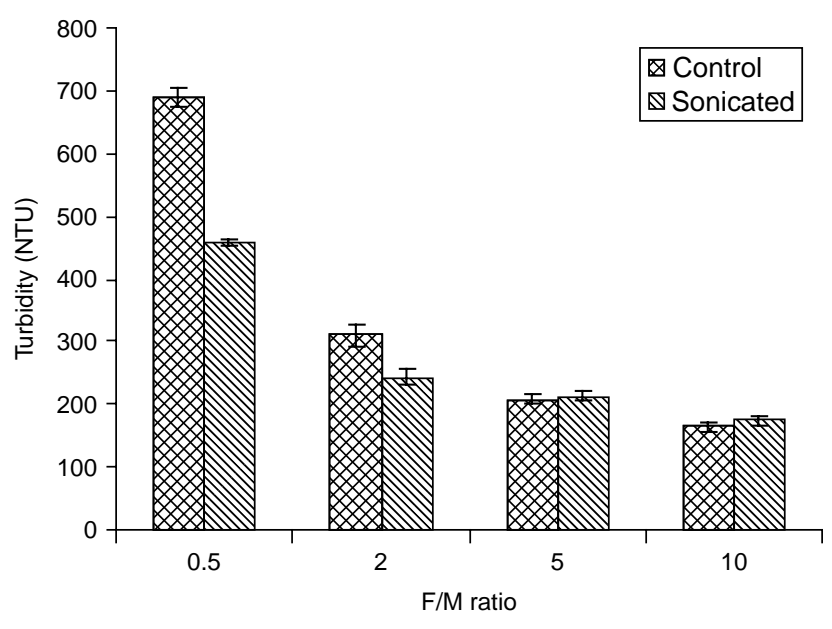

Figure 5 | Turbidity values of reactors at different F/M ratios after digestion.

This decline is higher for the reactor with $\mathrm{F} / \mathrm{M}$ ratio of 0.5 . When F/M ratio increases, the turbidities of sonicated reactors approach those of control reactors. However, general turbidity trend shows decrease by increasing F/M ratio as similarly observed for CST.

\section{CONCLUSIONS}

When sonication power and time were increased, soluble COD values also increased directly, indicating that the sludge flocs and cells were broken open and solubilized. These materials contributed to the soluble substrate during the batch anaerobic digester operation.

The control and sonicated reactors at different F/M ratios $(0.5,2,5$ and 10$)$ were operated as anaerobic digesters. Methane productions were lower at the beginning for higher F/M ratios. However, the gases produced at high $\mathrm{F} / \mathrm{M}$ ratio reactors overtook the ones from lower $\mathrm{F} / \mathrm{M}$ ratio reactors after a short time. At the end of reactor operation, calculated specific methane productions (ml/g TCOD added) indicated that the value from sonicated reactors at $\mathrm{F} / \mathrm{M}$ ratios of $0.5,2,5$ and 10 increased by $6.5,16,29$ and $32 \%$, compared to their control reactors. The reader should be reminded of the fact that $\mathrm{F} / \mathrm{M}$ ratio is a batch digester operating parameter. Therefore, the results presented here apply to digesters operated in batch mode and do not concern continuous digestion or cannot be scaled up to continuous digestion.
Also, the reductions in solids content and total COD increased with the sonication application and the increase in $\mathrm{F} / \mathrm{M}$ ratio. These findings indicate that sonication pretreatment of sludge with subsequent anaerobic digestion will help to minimize the sludge produced in a wastewater treatment plant.

The CST and turbidity values after digestion decreased with the increase in $\mathrm{F} / \mathrm{M}$ ratio possibly due to lower solids concentrations achieved.

\section{ACKNOWLEDGEMENTS}

This study was supported financially by TÜBİTAK -Turkish National Scientific and Research Council- as a part of Sludge Minimization Project (Project no: 105Y339).

\section{REFERENCES}

APHA AWWA WEF 2005 Standard Methods for the Examination of Water and Wastewater, 21st edition. American Public Health Association, American Water Works Association, Water Environment Federation, Washington, DC.

Appels, L., Baeyens, J., Degreve, J. \& Dewil, R. 2008 Principles and potential of the anaerobic digestion of waste activated sludge. Prog. Energy Combustion Sci. 34, 755-781.

Bougrier, C., Carrere, H. \& Delgenines, J. P. 2005 Solubilisation of waste-activated sludge by ultrasonic treatment. Chem. Eng. J. 106, 163-169.

Braguglia, C. M., Mininni, G., Tomel, M. C. \& Rolle, E. 2006 Effect of feed/inoculum ratio on anaerobic digestion of sonicated sludge. Water Sci. Technol. 54(5), 77-84.

Chu, C. P., Chang, B. V., Liao, G. S., Jean, D. S. \& Lee, D. J. 2001 Observations on changes in ultrasonically treated waste activated sludge. Water Res. 35, 1038-1046.

Eastman, J. A. \& Ferguson, J. F. 1981 Solubilization of particulate organic carbon during the acid phase of anaerobic digestion. JWPCF 53, 352-366.

Forster-Carneiro, T., Perez, M. \& Romero, L. I. 2008 Influence of total solid and inoculum contents on performance of anaerobic reactors treating food waste. Bioresour. Technol. 99, 6994-7002.

Grady, C. P. L. 1985 Biodegradation: its measurement and microbiological basis. Biotechnol. Bioeng. 27, 660-674.

Grönroos, A., Kyllönen, H., Korpijärvi, K., Pirkonen, P., Paavola, T. \& Jokela, J. 2005 Ultrasound assisted method to increase soluble chemical oxygen demand (SCOD) of sewage sludge for digestion. Ultrason. Sonochem. 12, 115-170. 
Hall, T. 198I Sonication for the study of floe strength and reflocculation of activated sludge. Environ Technol. Lett. 2, 579-588.

Hashimoto, A. G. 1989 Effect of inoculum/substrate ratio on methane yield and production rate from straw. Biol Wastes 28(4), 247-255.

Jirka, A. M. \& Carter, M. J. 1975 Micro semi automated analysis of surface and wastewaters for chemical oxygen demand; USEPA approved for reporting. Anal Chem. 47(8), 1397 (Approved by USEPA (1980) Fed. Regist. 45(78), 26811-26812).

Khanal, S. K., Grewel, D., Sung, S. \& Leeuwen, J. V. 2007 Ultrasound applications in wastewater sludge pretreatment: a review. Environ. Sci. Technol. 37, 277-313.

King, R. O. \& Forster, C. F. I99o Effects of sonication on activated sludge. Enzyme Microb. Technol. 12, 109-115.

Prashanth, S., Kumar, P. \& Mehrotra, I. 2006 Anaerobic degradability: effect of particulate COD. J. Environ. Eng. 132(4), 488-496.
Raposo, F., Banks, C. J., Siegert, I., Heaven, S. \& Borja, R. 2006 Influence of inoculum to substrate ratio on the biochemical methane potential of maize in batch tests. Process Biochem. 41(6), 1444-1450.

Shimizu, T., Kudo, K. \& Nasu, Y. 1993 Anaerobic waste-activated sludge digestion-a bioconversion mechanism and kinetic model. Biotechnol. Bioeng. 41, $1082-1091$.

Show, K. Y., Mao, T., Tay, J. H. \& Lee, D. J. 2006 Effects of ultrasound pretreatment of sludge on anaerobic digestion. J. Residuals Sci. Technol. 3(1), 51-59.

Wang, Q., Kuninobu, M., Kakimoto, K., Ogawa, H. I. \& Kato, Y. 1999 Upgrading of anaerobic digestion of waste activated sludge by ultrasonic pretreatment. Bioresour. Technol. 68, 309-313.

Wang, F., Lu, S. \& Ji, M. 2006 Components of released liquid from ultrasonic waste activated sludge disintegration. Ultrason. Sonochem. 13, 334-338. 